\title{
Application Research of Intake-Air Cooling Technologies in Gas-Steam Combined Cycle Power Plants in China
}

\author{
Tao Zhang, Zhitan Liu, Hongliang Hao, Lianchen Chang \\ GUODIAN Science and Technology Research Institute, Nanjing, China \\ Email: powerzhangtao@126.com
}

Received February 2014

\begin{abstract}
The generated power and efficiency of gas-steam combined cycle (GSCC) power plants depend on the temperature of the inlet air greatly. Based on the analysis of basic theory of inlet air cooling technologies, the application of evaporative cooling system and the absorption cooling system in GSCC power plants are discussed in this paper. Moreover, in China with high temperature and humidity, applied research and simulation analysis of the above two different cooling systems are conducted separately, the research results of which can provide certain reference for optimal design and economic operation of inlet air cooling system for GSCC power enterprises in China.
\end{abstract}

\section{Keywords}

Intake-Air Cooling; Combined Cycle; Application Research

\section{Introduction}

As a kind of clean energy, gas-powered plants have many advantages such as high energy conversion efficiency, less pollutants, start-stop fast, flexible operation, etc. In recent years, with the large-scale development and utilization of natural gas resources and the national "west to east gas pipeline project" in China, GSCC power plants have played an increasingly important role in electric power industry. By the end of 2013, there are nearly 160 gas power generation companies and 600 sets of gas turbine with the installed capacity of 43 million kilowatt, east China power grid gas-electric accounts for $56.6 \%$ and southern grid accounts for $23.7 \%$.

The gas turbine is a kind of constant volume equipment, output and efficiency of which is highly affected by the environmental conditions. When the inlet air temperature rises, the temperature ratio and equivalent flow of air and reduced speed of gas turbine will decrease, which will result in performance of the gas turbine degeneration.

According to related literature, depending on the type of the gas turbine, the electric output will decrease by a percentage between $6 \%$ and more than $10 \%$ for every $10{ }^{\circ} \mathrm{C}$ of intake-air temperature increase. At the same time, the specific heat consumption increase by a percentage between $1.5 \%$ and more than $4 \%$. However, generally the high temperature period is the moment when the power grid needs gas turbines taking part in peak regulation 
increase output, as shown in Figure 1.

The characteristic that gas turbine power plant performance is affected by the environment temperature has aroused widespread attention. If it were possible to obtain a constant low inlet air temperature, a constant high power output could be generated from a gas turbine. Now inlet cooling technologies has been applied in practice. As is known, in east and south of China where a large number of gas turbines are used for generation, meanwhile the annual average temperature in these regions is higher than others, This paper, through studying on the inlet air cooling technologies applied in GSCC power plants, provides certain reference for optimal design and economic operation of inlet air cooling system in China.

\section{The influences of Air Temperature on Gas Turbine Performance}

\subsection{Analysis of the Influence of the Temperature on Gas Turbine Performance}

Atmospheric temperature has great influences on power and efficiency of simple cycle and combined cycle of gas-powered plant. At present, the number of importing heavy-duty gas turbines is increasing year by year, therefore it is very significant and valuable to study on the effects of temperature on large GSCC power performance. Taking GE PG9371FB, Mitsubishi M701F4, Siemens SGT5-4000F (4) which are the most advanced heavy-duty gas turbine model in China for instance, some aspects of the mentioned issues are being discussed, l, as shown in Figures 2 and 3.

As we can see from the Figure 2, the output of these three kinds of gas turbine units reduce greatly as the temperature rises. Taking GE PG9371FB as a example, for gas turbine simple cycle, the load at $28^{\circ} \mathrm{C}$ is approximately about $30 \mathrm{MW}$ lower than ISO design condition $\left(15^{\circ} \mathrm{C}\right)$, similarly, for gas-steam combined cycle, the load at $28^{\circ} \mathrm{C}$ decrease about $40 \mathrm{MW}$.

The Figure 3 shows that temperature has a greater influence on efficiency of those three kinds of model's combined cycle. The influence on GE unit is most prominent. When the temperature is $28^{\circ} \mathrm{C}$, its efficiency is

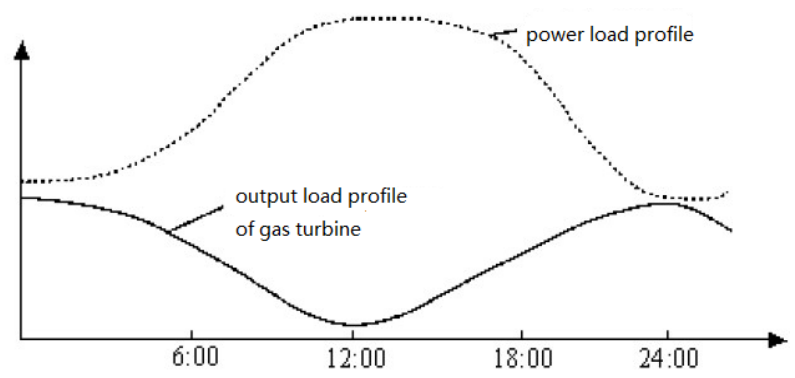

Figure 1. Relation curve between power load and gas turbine load.

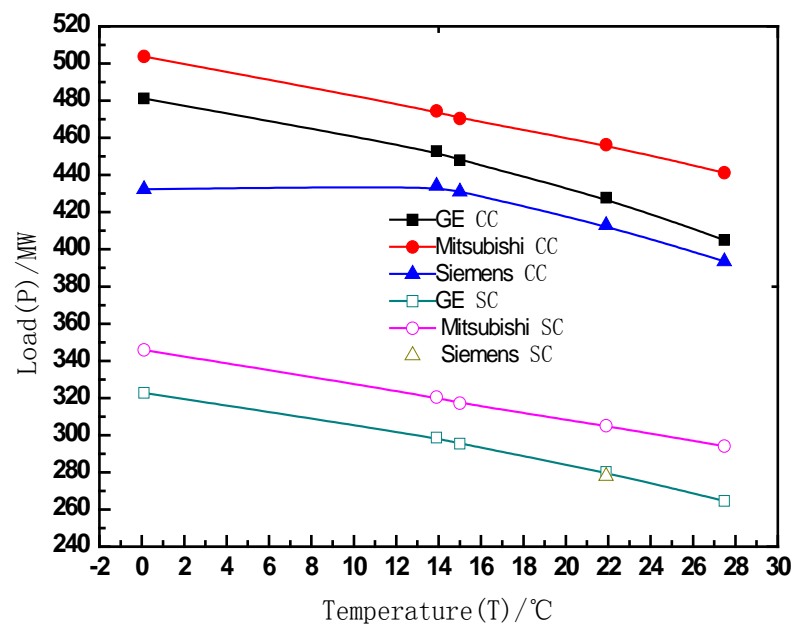

Figure 2. P-T curves of GSCC units at full power load. 


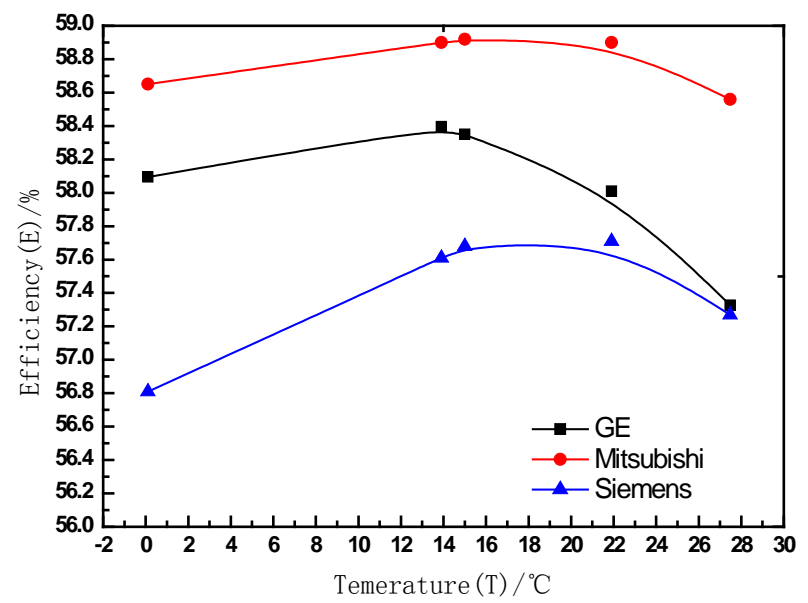

Figure 3. E-T curves of GSCC units at full power load.

$57.3 \%$, which is $1 \%$ lower than the ISO design condition. From the above analysis, we can get a conclusion that temperature has a very significant influence on the performance of gas turbine units.

\subsection{Theoretical Analysis of Effecting of the Temperature on Performance of Gas Turbine}

If the inlet air temperature rises, efficiency and output of the gas turbine will reduce. Conversely, they will increase when the temperature drops. For simple cycle gas turbine, the main reasons are as following:

1) When the temperature of the air increases, the air density and, consequently, the air mass flow decreases. The reduced air mass flow directly causes the gas turbine to produce less power output. The ideal gas state equation,

$$
\frac{P_{1}}{\rho_{1} T_{5}}=\frac{\dot{P_{1}}}{\dot{\rho}_{1} \dot{T}_{5}}
$$

where, $P_{1}, T_{5}$ and $\rho_{1}$ are respectively air pressure, air temperature and air density, and $\dot{P}_{1}, \dot{T}_{5}$ and $\dot{\rho}_{1}$ are respectively air pressure, air temperature and air density after the inlet air temperature changes. Usually, the air pressure basically remains unchanged. When the inlet air temperature declines, air density will rise obviously and the air volume of gas turbine will increase, so the power output will also increase accordingly.

2) By the Thermodynamics, the lower the temperature of gas is, the lower the speed of its molecular movement is. So the smaller compression work is needed to achieve the same pressure. The equations are as follows:

$$
\begin{gathered}
W_{c}=C_{p} T_{1}\left(\pi^{m}-1\right) \\
W_{G T}=W_{T}-W_{C}=C_{p} T_{1}\left[\tau\left(1-\pi^{-m}\right)-\left(\pi^{m}-1\right)\right] \\
\lambda=1-\frac{W_{C}}{W_{T}}=1-\frac{T_{1}\left(\pi^{m}-1\right)}{T_{3}\left(1-\pi^{-m}\right)}=1-\frac{\pi^{m}}{\tau}
\end{gathered}
$$

where, $W_{G T}$ is power output of the ideal cycle, $W_{T}$ is expansion power, $W_{C}$ is consumption work of compressor, $C p$ is air specific heat at constant pressure, T1 is atmospheric temperature, $\pi$ is pressure ratio, and $\tau$ is temperature ratio. $m=(\kappa-1) / \kappa, \kappa$ is adiabatic index, $\lambda$ is coefficient of useful work.

Because the gas turbine output power is the difference between gas turbine expansion power and compressor consumption work from the above equations, the higher intake-air temperature results in an increase of the specific compressor work and, therefore, in a further reduction of the power output [1].

\section{Fogging Evaporation System and Application}

Gas turbine cooling technologies can be divided into two categories: evaporative cooling and refrigeration cooling. The former is mainly divided into media type evaporative cooling and the fogging cooling based on the 
structure of the cooler; the latter is divided into compression refrigeration cooling, absorption refrigeration cooling, and cold storage cooling according to the ways to obtain energy source. This paper focuses on the analysis of fogging evaporative cooling and absorption cooling system which are the typical two kinds of inlet air cooling technologies.

\subsection{Theoretical Analysis}

Fogging evaporative cooling is a common method for gas turbine inlet air cooling, a typical fogging cooling system is as shown in Figure 4(a). And the corresponding cooling process is presented in Figure 4(b). It is assumed that, 1) GTCC inlet fogging is adiabatic humidifying process; 2) The capacity (or number of high-pressure pumps) of inlet fogging system is designed large enough; 3) the fogdrop diameter is small enough and heat exchange efficiency of fogging approximates 100\%. Thus, GTCC inlet air temperature can be cooled to wet bulb temperature by fogging. Inlet air cooling process through evaporative media coolers is similar to the inlet fogging process, except that compressor inlet air cannot reach saturated state.

\subsection{Analysis of Cases}

In the 1980s, the fogging cooling system of gas turbine was firstly adopted. Direct inlet fogging is a method of cooling where demineralized water is converted into a fog by means of special atomizing nozzles operating at 138 bar 2000 psi. Details pertaining to the thermodynamics and practical aspects of fogging have been described in Meher-Homji. The fog provides cooling when it evaporates in the air inlet duct of the gas turbine. This technique allows close to $100 \%$ effectiveness in terms of attaining $100 \%$ relative humidity at the gas turbine inlet and thereby gives the lowest temperature possible the wet bulb temperature without refrigeration. Direct high pressure inlet fogging can also be used to create a compressor inter cooling effect by allowing excess fog into the compressor, thus boosting the power output considerably. At present, the comparatively advanced fogging cooling system has combined inlet air cooling technologies and wet compression technology together [1].

M. e Lucia [2] made four cooling schemes for Gas turbine LM6000 cogeneration units: A) double stage absorption system; B) single stage absorption refrigeration; C) evaporative cooling; D) evaporative cooling combined with absorption cooling. Single stage and two-stage absorption refrigeration's power is $3300 \mathrm{~kW}$. Which is sufficient to enable to cool the intake air down from $25^{\circ} \mathrm{C}\left(60 \%\right.$ relative humidity) to $10^{\circ} \mathrm{C}$. In this paper, the cooling systems were used in north (Region 1, north latitude 45.08' and there is about 3500 hours which the

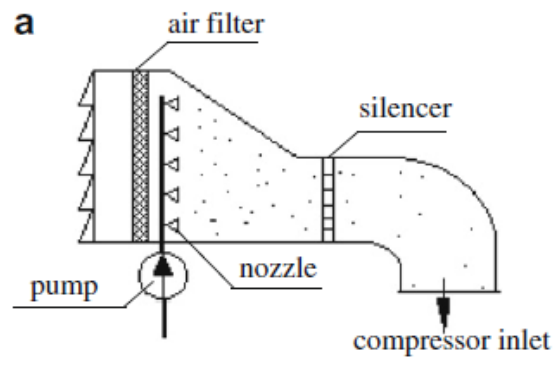

(a) Schematic of fogging evaporation cooling

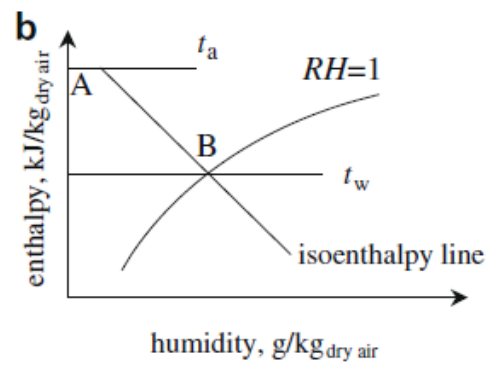

(b) The process of fogging cooling

Figure 4. Schematic of fogging cooling system. 
temperature is higher $15^{\circ} \mathrm{C}$ throughout a year) and south (north latitude 38.13' and there is about 5300 hours )Italy. The changers of performance of combined cycle gas turbine are shown as Table $\mathbf{1}$.

At the same time, we have conducted an experiment through applying the fogging cooling system in a GCSS power plant with gas turbine GE 9171E which is Located in east China. The changes of temperature of inlet air and performance of gas turbine are shown in Figures $\mathbf{5}$ and $\mathbf{6}$.

Using of fogging evaporation cooling system, the ambient temperature was dropped from $33.8^{\circ} \mathrm{C}$ to $27.0^{\circ} \mathrm{C}$, and as a result, the average of output of gas turbine combined cycle was increased from 95.5 MW to 99.5 MW. The power output of combined cycle was improved by $5 \%$ approximately.

\section{Absorption Cooling System and Applications}

\subsection{Theoretical Analysis}

The absorption refrigeration cooling system and the cooling process are presented in Figure 7, where the system is mainly composed of a GSCC power unit, twin sets of single-effect hot-water driven water/LiBr absorption chillers, and air coolers.

In the system, the hot flue gas from the gas turbine exhaust is used to generate the steam in a heat recovery steam generator (HRSG). The steam which is from HRSG or steam turbine is usually used in a double-effect lithium-bromide absorption chiller to produce the chilled water. A compact heat exchanger should be designed for installation at the compressor inlet duct. The chilled water from the absorption chiller flows through the heat exchanger and cools the inlet air.

Inlet air cooling process is shown in Figure 7(b), where the inlet air temperature is cooled from the ambient temperature ta to $\mathrm{t} 1$. The point $\mathrm{B}$ refers to the apparatus dew point of air coolers and its relative humidity is generally assumed as 0.95 . The point $\mathrm{D}$ is dew point of the ambient. When the chilled water temperature tcs $<\mathrm{tD}$, condensed water separates out from humid air and the air coolers operates under wet conditions.

\subsection{Analysis of Cases}

Mohanty [3] studied this system for a 100 MW gas turbine in Bankok. The increase in the power output was

Table 1. The changes of output and fuel consumption.

\begin{tabular}{ccccc}
\hline \multirow{2}{*}{$\begin{array}{c}\text { Relative to no-cooling } \\
\text { system (\%) }\end{array}$} & \multicolumn{3}{c}{ Region1 } & \multicolumn{2}{c}{ Region 2 } \\
\cline { 2 - 5 } Plan 1 & Output increasing & Fuel increasing & Output increasing & 8.2 \\
Plan 2 & 5.4 & 4.9 & 9.7 & 3.7 \\
Plan 3 & 5.2 & 4.9 & 3.8 & 3.3 \\
Plan 4 & 2.7 & 5.2 & 9.7 \\
\hline
\end{tabular}

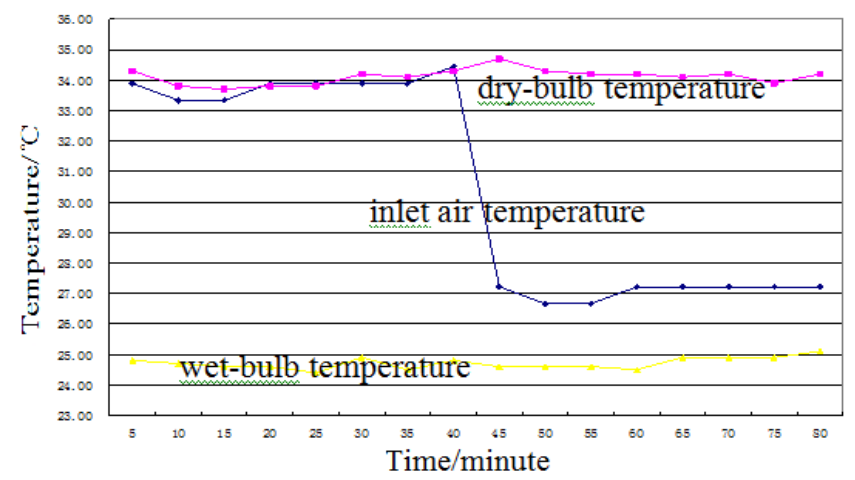

Figure 5. Temperature-Time curves of GSCC units with inlet air cooling. 


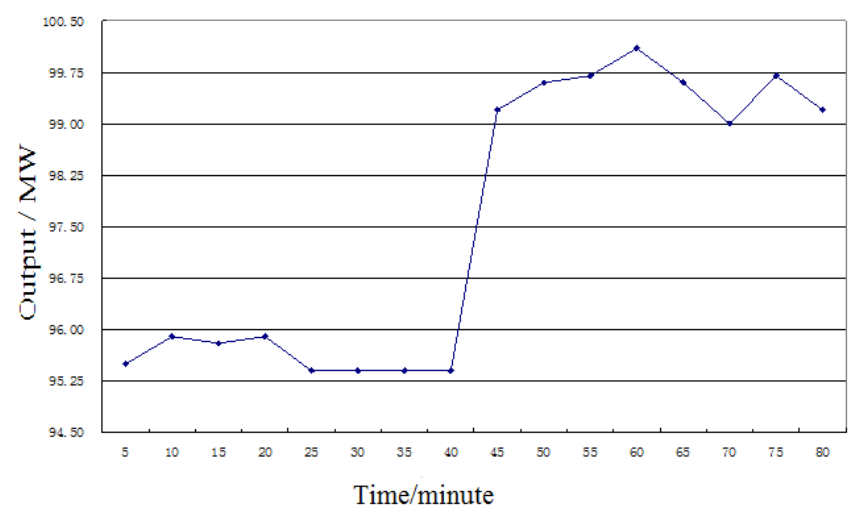

Figure 6. Output-Time curves of GSCC units units with inlet air cooling.

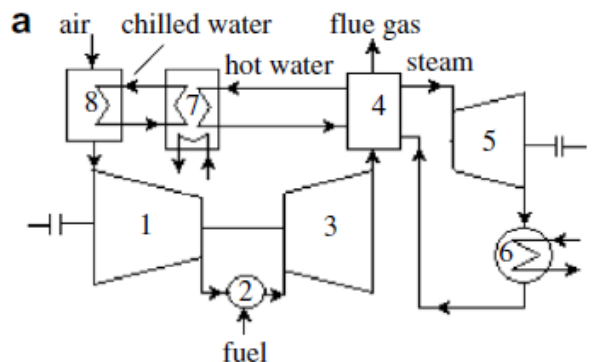

1-comperssor; 2-combustor; 3-turbine; 4-HRSG; 5-steamturbine; 6-condenser; 7-absorption chiller; 8-air cooler

(a) Schematic of GSCC plant with absorption chiller

b

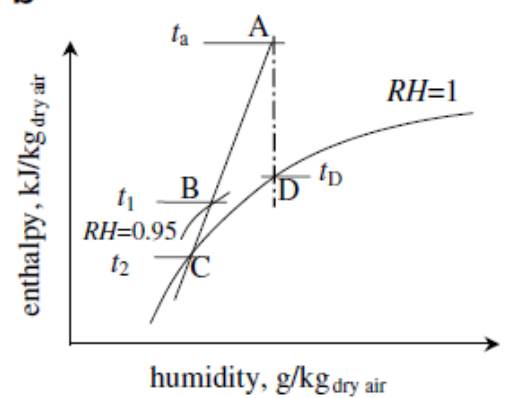

(b) Cooling process of chiller

Figure 7. Schematic of GSCC plant with absorption chiller.

11\%. Also, this system has been analyzed in detail by Bies [4]. Toshiba Corporation has installed a hybrid inlet air cooling system for a 5.42 MW gas turbine. This system includes an absorption chiller and a thermal energy storage system. It cools the inlet air to the gas turbine from $38^{\circ} \mathrm{C}$ to $15^{\circ} \mathrm{C}$. The capacity of the storage system is $35 \%$ of the total system capacity. M. Ameri [5] studied the intake air-cooling system that uses a steam absorption chiller in the Chabahar power plant. By using this technique the output power can increase by $11.3 \%$. The economical studied have shown the internal rate of return would be $23.4 \%$. The payback period was estimated to be around 4.2 years.

Shenzhen Jin Gang gas turbine power plant is the earliest power plant which use absorption chiller cooling [6]. The type of gas turbine is GE 6B, and the steam which is extracted from HRSG is used in a double-effect lithium-bromide absorption chiller to produce the chilled water. The transformation results show that with the cooling system, excellent effects have been achieved. When the inlet air temperature is $31^{\circ} \mathrm{C}$ and humidity is $75 \%$, the intake air temperature is dropped by $14^{\circ} \mathrm{C}$, gas turbine power is increased by $3.94 \mathrm{MW}$ (advanced $13.5 \%$ 
nearly), steam turbine power is increased by 1.3 MW (advanced 10.6\% nearly), therefore, GSCC power increase 5.24MW (advanced 12.68\%) and efficiency is increased by $3.2 \%$.

A GSCC power plant with the gas turbine 9E of Guangzhou city adopt lithium bromide absorption chiller cooling. In the cooling system, COP (performance coefficient of chiller) is 1.41, the outlet temperature of steam is $90^{\circ} \mathrm{C}$, heat source of refrigerating is from low pressure steam of HRSG, and the inlet temperature is designed to be cooled to $22.1^{\circ} \mathrm{C}$. Based on the above basic parameters, the method of simulation analysis is conducted to analyze the performance of GSCC power plant.

From Figures 8 and 9, we can know that the output of gas turbine combined cycle increases from 147.28 MW to $158.19 \mathrm{MW}$ and the efficiency increases from $33.92 \%$ to $34.53 \%$ after taking absorption chiller cooling system. However, the output of steam turbine reduces from 75.41 MW to 74.65 MW and its efficiency reduces from $30.27 \%$ to $29.39 \%$, the reason of decline is that some low pressure steam is been drawn from HRSG. Furthermore, the whole power output of combined cycle increases from 222.42 MW to 232.84 MW, but the efficiency of combined cycle decreases slightly, which is consistent with the simulation result of GSCC power plant with the inlet air cooling system by the Greek scholar E. kakarsa [7].

\section{Conclusions}

Based on the effect of the temperature on the performance of GSCC power plants, the paper shows the necessity of inlet air cooling technologies. The main conclusions are as follows:

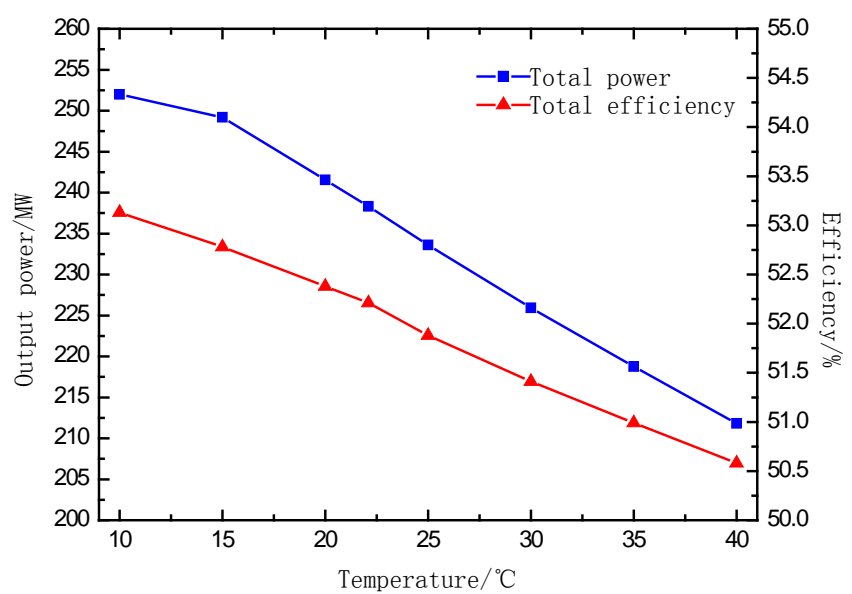

Figure 8. The influence of inlet air temperature on the gas turbine combined cycle.

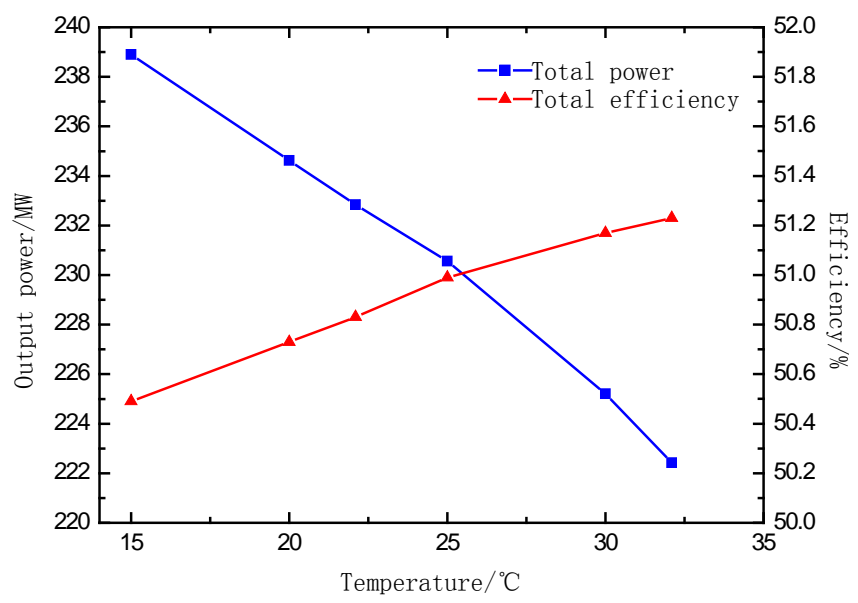

Figure 9. The influence of inlet air cooling on the gas turbine combined cycle. 
1) Adopting inlet air cooling technologies, the output and efficiency of gas turbine combined cycle units can be improved generally.

2) The surrounding temperature is significant to choose which kind of the cooling technologies. Fogging evaporative cooling technology can reduce the inlet air temperature effectively, and it is suitable for gas turbine power plant which needs a lower cooling requirements.

3) Absorption chiller cooling technology has advantages of wide range of adjustments and cooling degrees, which is suitable for various kinds of gas turbine power plants. Simulation results show that using steam as cooling medium may affect the efficiency of combined cycle, so we should take comprehensive consideration before adopting the technology, and select the appropriate temperature drop ranges.

\section{References}

[1] Jiao, S.J. (2007) The Gas Turbine and Gas-Steam Combined Cycle Unit. China Power Press, Beijing.

[2] Sigler, J. and Erickson, D. (2001) Gas Turbine Inlet Air Cooling Using Absorption Refrigeration: A Comparison Based on a Combined Cycle Process. Proceedings of ASME TURBO EXPO, ASME, New Orleans.

[3] Mohanty, B. and Paloso, J. (1995) Enhancing Gas Turbine Performance by Intake Air Cooling Using an Absorption Chiller. Heat Recovery Systems and CHP, 15, 41-50. http://dx.doi.org/10.1016/0890-4332(95)90036-5

[4] Bies, D., Johantgen, U. and Scharfe, J. (1999) Optimised Cooling of the Compressor Intake Air: A New Way for the Improvement of Power and Efficiency in Gas Turbine Plants. Proceedings of the International Gas Turbine Congress, Kobe.

[5] Ameri, M. and Hejazi, S.H. (2004) The Study of Capacity Enhancement of the Chabahar Gas Turbine Installation Using an Absorption Chiller. Applied Thermal Engineering, 24, 59-68. http://dx.doi.org/10.1016/S1359-4311(03)00239-4

[6] Hu, D. (2009) Reduce the Effect of Inlet Temperature on Output Capacity of Gas Turbine. Industrial Technology, No. 25

[7] Kakaras, E., Doukelis, A. and Karellas, S. (2002) Compressor Intake Air Cooling in Gas Turbine Plants. Proceedings of ECOS, ECOS, Berlin, 845-851. 